\title{
Mobilization with cyclophosphamide reduces the number of lymphocyte subpopulations in the leukapheresis product and delays their reconstitution after autologous hematopoietic stem cell transplantation in patients with multiple myeloma
}

\author{
Matevz Skerget ${ }^{1}$, Barbara Skopec ${ }^{1}$, Darja Zontar ${ }^{1}$, Peter Cernelc ${ }^{1}$ \\ ${ }^{1}$ Department of hematology, University Medical Center Ljubljana, Ljubljana, Slovenia
}

Radiol Oncol 2016; 50(4): 402-408.

Received 19 October 2015

Accepted 31 January 2016

Correspondence to: Matevz Škerget, M.D., Department of Hematology, University Medical Center Ljubljana, Zaloška cesta 2, 1000 Ljubljana, Slovenia. Phone: +386 1522 3139; Email: matevz.skerget@kclj.si

Disclosure: MS, BS and PC received speaker's honoraria from Amgen. The authors declare that they have no other conflicts of interest.

\begin{abstract}
Background. Autologous hematopoietic stem cell transplantation is considered the standard of care for younger patients with multiple myeloma. Several mobilization regimens are currently used, most commonly growth factors alone or in combination with chemotherapy. The aim of our study was to investigate the differences in lymphocyte subpopulation counts between three different mobilization regimens on collection day, in the leukapheresis product and on day 15 after autologous hematopoietic stem cell transplantation.

Patients and methods. In total 48 patients were prospectively enrolled in three different mobilization regimens; (i) filgrastim (20), (ii) pegfilgrastim (19) and (iii) cyclophosphamide + filgrastim (9). Lymphocytes, CD16+/56+ natural killer and CD4+/CD25 high T regulatory cells were determined by flow cytometry.

Results. We found a statistically significant difference between the mobilization regimens. Cyclophosphamide reduced lymphocyte and natural killer (NK) cell counts on collection day (lymphocytes $1.08 \times 10^{\circ} / \mathrm{L}$; NK cells $0.07 \times 10^{\circ} / \mathrm{L}$ ) compared to filgrastim (lymphocytes $3.08 \times 10^{9} / \mathrm{L}$; NK cells $0.52 \times 10^{9} / \mathrm{L}$ ) and pegfilgrastim (lymphocytes $3 \times 10^{9} / \mathrm{L}$; NK cells $0.42 \times 10^{9} / \mathrm{L}$ ). As a consequence lymphocyte and NK cell counts were also lower in the leukapheresis products following cyclophosphamide mobilization regimen (lymphocytes $50.1 \times 10^{9} / \mathrm{L}$; NK cells $4.18 \times 10^{9} / \mathrm{L}$ ) compared to filgrastim (lymphocytes $112 \times 10^{9} / \mathrm{L}$; NK cells $17.5 \times 10^{9} / \mathrm{L}$ ) and pegfilgrastim (lymphocytes $112 \times 10^{9} / \mathrm{L}$; NK cells $14.3 \times 10^{9} / \mathrm{L}$ ). In all mobilization regimens $T$ regulatory cells increased 2 -fold on collection day, regarding the base line value before mobilization. There was no difference in T regulatory cell counts between the regimens.

Conclusions. Mobilization with cyclophophamide reduces the number of mobilized and collected lymphocytes and NK cells as compared to mobilization with growth factors only and results in their delayed reconstitution following autologous hematopoietic stem cell transplantation. We found no difference between filgrastim and pegfilgrastim mobilization.
\end{abstract}

Key words: mobilization; myeloma; cyclophosphamide; NK cell; stem cell transplantation

\section{Introduction}

Novel agents have significantly increased the response rate and overall survival (OS) of patients with multiple myeloma (MM), but high-dose chemotherapy and autologous hematopoietic stem cell transplantation (AHSCT) are still considered the standard of care for younger patients. ${ }^{1-5}$ Several 
TABLE 1. Patient characteristics

\begin{tabular}{|c|c|c|c|c|}
\hline Characteristics & Total number of patients & G-CSF mobilization & $\begin{array}{l}\text { Pegfilgrastim } \\
\text { mobilization }\end{array}$ & $\begin{array}{l}\text { Cyclophosphamide } \\
\text { mobilization }\end{array}$ \\
\hline Numbers & 48 & 20 & 19 & 9 \\
\hline Median age (Range) years & $61(35-71)$ & $60(35-69)$ & $64(51-71)$ & $59(42-63)$ \\
\hline ISS stage $1 / 2 / 3$ & $13 / 17 / 18$ & $3 / 8 / 9$ & $7 / 7 / 5$ & $3 / 2 / 4$ \\
\hline Patients with prior radiotherapy & 11 & 3 & 8 & 0 \\
\hline Response VGPR/PR/SD & & $11 / 9 / 0$ & $10 / 8 / 1$ & $3 / 5 / 1$ \\
\hline Poor mobilizers & 3 & 1 & 2 & 0 \\
\hline
\end{tabular}

$F=$ female; $G-C S F=$ filgrastim; ISS = international staging system; $M=$ male; $P R=$ partial response; $S D=$ stable disease; VPGR = very good partial response

mobilization regimens are currently used, most commonly growth factors alone or in combination with chemotherapy. Considering growth factors, the most commonly used are filgrastim (G-CSF) and the long acting pegfilgrastim..$^{6-8}$

The combination of chemotherapy and growth factors is commonly used for mobilization because of the higher yield of stem cells and fewer collection procedures.6,9 Usually, chemotherapy regimens include cyclophosphamide at different doses. Intermediate dose cyclophosphamide (3 - 4 $\mathrm{g} / \mathrm{m}^{2}$ ) significantly increases the proportion of patients achieving the target dose of collected stem cells as compared to low dose cyclophosphamide $\left(1.5 \mathrm{~g} / \mathrm{m}^{2}\right)$ with a significantly faster neutrophil and platelet engraftment, probably due to a higher dose of infused stem cells. ${ }^{10}$

Cyclophosphamide induces bone marrow aplasia followed by delayed reconstitution of lymphocytes resulting in partial recovery on collection day. ${ }^{11}$ As a consequence lower doses of lymphocytes are collected and reinfused. There is accumulating evidence that the dose of infused lymphocytes and their recovery on day 15 and 30 after AHSCT are independent prognostic factors for overall survival in patients with non-Hodgkin lymphomas and myeloma. ${ }^{12-15}$ Among lymphocyte subpopulations the CD16+/56+ natural killer (NK) cells are particularly strong independent predictors of survival. ${ }^{12}$

$\mathrm{T}$ regulatory (Treg) cells express CD4+CD25 high and are crucial in the tolerance to self-antigens. Since tumor antigens are derived from self-antigens, Treg cells may decrease the antimyeloma effect. Treg cells directly inhibit NK cell effector function and Treg depletion exacerbates NK cell proliferation and cytotoxicity in in-vitro essays. . $^{16,17}$
In $\mathrm{MM}$ the induction of immunosupression by Treg cells is believed to be associated with myelomagenesis and the progression of MM. ${ }^{18,19}$ The effect of cyclophosphamide on Treg cells depends on the dose of cyclophosphamide and the addition of G-CSF. Low doses of cyclophosphamide have a specific toxicity to Treg cells, thereby decreasing their numbers and potentially increasing an immune response against myeloma cells. ${ }^{20}$ On the opposite, high doses of cyclophosphamide in combination with G-CSF increase the number of Treg cells by $2-3$ fold. ${ }^{11}$ The aforementioned data support the role of immunosurveillance on the progression of $\mathrm{MM}$ and the concept of an autologous graft-versus-myeloma effect in AHSCT.

The aim of this study was to investigate the influence of three different mobilization regimens (i) filgrastim, (ii) pegfilgrastim and (iii) cyclophosphamide + filgrastim on the lymphocyte subpopulations during the mobilization procedure, in the leukapheresis product and after AHSCT. To the best of our knowledge, ours is the first study to compare the effects of three different mobilization regimens on lymphocyte subpopulations in newly diagnosed patients with MM after novel agent induction.

\section{Patients and methods}

In all, 48 patients with newly diagnosed symptomatic MM following induction treatment with bortezomib and dexamethasone were enrolled into this prospective single center study to receive stem cell mobilization with three different regimens; (i) filgrastim, (ii) pegfilgrastim and (iii) cyclophosphamide + filgrastim in a $2: 2: 1$ ratio. Patients 
were enrolled by two of the authors (MS, BS) to achieve same baseline characteristics according to age, number of treatment cycles, sex, ISS stage and response to induction treatment (Table 1). Only newly diagnosed MM patients that received induction treatment with 3 - 6 cycles of bortezomib $\left(1.3 \mathrm{mg} / \mathrm{m}^{2} \mathrm{sc}\right.$. on days $1,4,8$ and 11$)$ and dexamethasone (40 mg iv. on days 1-4 of cycle 1 and on days 1, 4, 8 and 11 of the following cycles) were enrolled. Response before enrollment was assessed according to IMWG criteria. ${ }^{21}$ Since a bone marrow biopsy is considered mandatory for defining complete response (CR), none of the patients in our study was considered in CR before mobilization, as a bone marrow biopsy was not mandatory at the time of enrollment. Patients with treatment refractory MM were excluded. This study was approved by the Local Ethics Committee (Number 149/04/11) and all patients gave their informed consent according with the Declaration of Helsinki.

\section{Peripheral blood stem cell mobilization}

Filgrastim mobilization: Patients received subcutaneous filgrastim $10 \mathrm{mcg} / \mathrm{kg}$ (rounded up to 300 mcg or $480 \mathrm{mcg}$ vial size or combination thereof) daily for five days. Peripheral circulating CD34+ cells monitoring was commenced on day five and apheresis was commenced at CD34+ levels greater than $20 \times 10^{6} / \mathrm{L}$. Additional filgrastim was allowed on day 6 .

Pegfilgrastim mobilization: Patients received a fixed subcutaneous dose of $12 \mathrm{mg}$ pegfilgrastim on day one. Peripheral circulating CD34+ cells monitoring was commenced on day five and apheresis was commenced at CD34+ levels greater than $20 \times$ $10^{6} / \mathrm{L}$. No additional growth factors were allowed.

Patients received cyclophosphamide $4 \mathrm{~g} / \mathrm{m}^{2}$ intravenous with mesna prophylaxis. Subcutaneous filgrastim $10 \mathrm{mcg} / \mathrm{kg}$ was started on day 5 . Peripheral circulating CD34+ cells monitoring was commenced on day five and apheresis was commenced at CD34+ levels greater than $20 \times 10^{6} / \mathrm{L}$. Filgrastim was continued daily until completion of apheresis or for up to day 20.

\section{Blood samples and flow cytometry}

Ethylenediaminetetraacetic acid (EDTA) anticoagulated peripheral blood samples were obtained from all patients at three time points; (i) before mobilization, (ii) on collection day and (iii) on day fifteen after AHSCT. A sample of the leukapheresis product was obtained on day one of collection. The immunolabeling was performed on samples according to the manufacturer's recommendation. Samples were incubated with 10-20 $\mu \mathrm{L}$ of antibody in the dark for 20 minutes. Red blood cells were then lysed. NK cells were enumerated as CD16+/56+ cells and Treg cells were enumerated as CD4+CD25 $5^{\text {high }}$ cells. Samples were analyzed using Immunotech (Beckman-Coulter) antibodies on the Beckman Coulter Cytomics FC500 analyzer.

\section{Stem cell collection target and definition of poor mobilizers}

The collection of at least $2 \times 10^{6} \mathrm{CD} 34+$ cells $/ \mathrm{kg}$ recipient body weight was required. Patients with a circulating CD34+ cell count below $20 \times 10^{6} / \mathrm{L}$ up to six days after mobilization with filgrastim and pegfilgrastim or up to twenty days after cyclophosphamide and filgrastim or patients with a yield of less than $2 \times 10^{6} \mathrm{CD} 34+$ cells $/ \mathrm{kg}$ in three apheresis procedures were considered poor mobilizers and were excluded from further evaluation. ${ }^{22}$

\section{High-dose therapy and AHSCT}

AHSCT was planned 20-40 days after successful stem cell collection. Patients received melphalan $\left(200 \mathrm{mg} / \mathrm{m}^{2}\right)$ and stem cells were reinfused 24 hours later. ${ }^{3,5,23}$ The mean stem cell dose was $2.6 \times$ $10^{6} \mathrm{CD} 34+$ cells $/ \mathrm{kg}, 2.6 \times 10^{6} \mathrm{CD} 34+$ cells $/ \mathrm{kg}$ and 3.1 $\times 10^{6} \mathrm{CD} 34+$ cells $/ \mathrm{kg}$ for patients after filgrastim, pegfilgrastim and cyclophosphamide + filgrastim mobilization respectively. Patients received prophylaxis with levofloxacin and posaconazole, and G-CSF support until leukocyte engraftment at the discretion of the treating physician.

\section{Statistical analysis}

The SPSS Statistics 21 (IBM, USA) software package was used for the statistical analysis. One-way ANOVA test was used to calculate differences between cohorts. Additional post-hoc analysis using the Tukey's HSD test was used to validate differences between two cohorts. For difference between only two cohorts the t-test for independent samples was used. Results were considered statistically significant if $\mathrm{p}<0.05$.

\section{Results}

No differences between the three regimens were noted in lymphocyte, NK cell and Treg cell counts 
Mean lymphocyte count before mobilization and on collection day with $95 \% \mathrm{CI}$

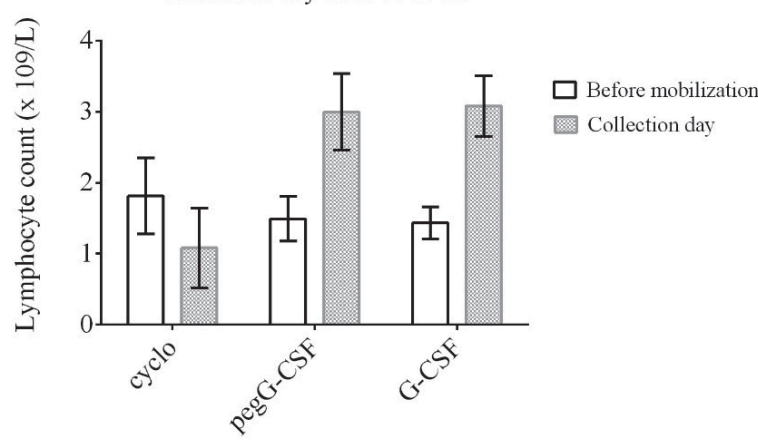

Mean NK cell count before mobilization and on collection day with $95 \% \mathrm{CI}$

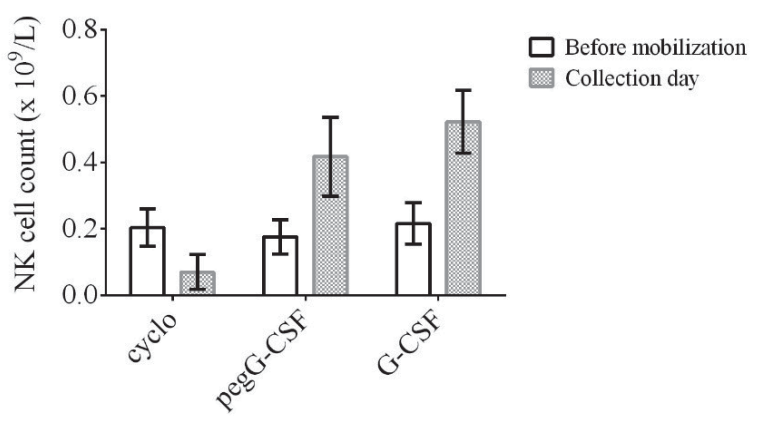

Mean Treg cell count before mobilization and on collection day with $95 \% \mathrm{CI}$

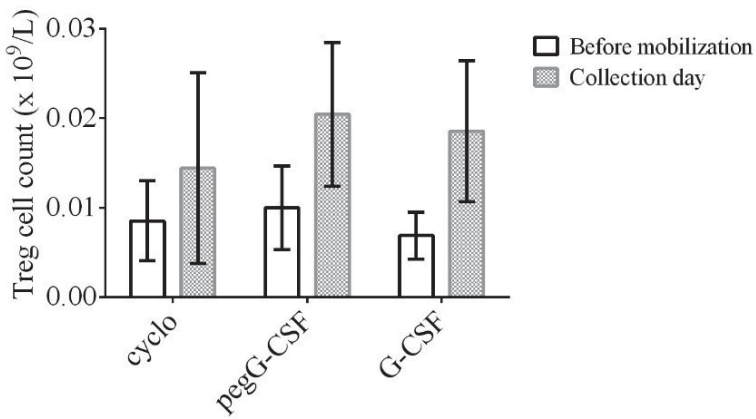

FIGURE 1. The mean lymphocyte, natural killer (NK) cell and Treg cell counts (109/L) before mobilization and on collection day with $95 \%$ confidence interval $(\mathrm{Cl})$ for mobilization with cyclophosphamide (cyclo), pegfilgrastim (pegG-CSF) and filgrastim (G-CSF).

before mobilization. Mobilization with cyclophosphamide reduced the lymphocyte and NK cell counts on collection day by 2 -fold as compared to baseline value before mobilization. On the contrary mobilization with G-CSF and pegfligrastim induced a 2-fold increase in lymphocyte and NK cell counts on collection day as compared to baseline value before mobilization (Figure 1). This resulted in different lymphocyte and NK cell counts on collection day between the mobilization regimens $(p$
$<0.001$ ). In pairwise comparison the differences between mobilization with cyclophosphamide and G-CSF only, and cyclophosphamide and pegfilgrastim only were statistically significant $(\mathrm{p}<$ 0.001). The differences in lymphocyte and NK cell counts on collection day resulted in a significantly different lymphocyte and NK cell composition of the leukapheresis product (Table 2). All three mobilization regimens increased Treg cell counts on collection day by 2 -fold with no differences in absolute values between the three regimens. Comparison between the groups mobilized with G-CSF or pegfilgrastim showed no difference in lymphocyte, NK and Treg cell counts on the collection day, in the leukapheresis product and on day 15 after AHSCT. Because no difference in lymphocyte and NK cell counts during mobilization and in the leukapheresis product was noted between the G-CSF and pegfilgrastim group, and due to the small patient sample, we analyzed lymphocyte counts on day 15 after AHSCT between cyclophosphamide mobilization and growth factors only (G-CSF and pegfilgrastim combined) mobilization. Mobilization with growth factors resulted in a higher lymphocyte count on day 15 post AHSCT compared to cyclophosphamide mobilization $(\mathrm{p}<$ $0.04)$.

Three patients failed mobilization with G-CSF or pegfilgrastim and were excluded from further evaluation. All three were salvaged with plerixafor and successfully underwent AHSCT. No patient failed mobilization with cyclophosphamide. All transplanted patients successfully engrafted.

\section{Discussion}

The use of cyclophosphamide mobilization in MM patients results in lower mobilization failure, higher stem cell yield and fewer collection procedures but at the cost of higher toxicity. ${ }^{6,9,10}$ Furthermore, cyclophosphamide affects lymphocyte subpopulations possibly affecting the response after AHSCT. In our study, we prospectively analyzed the impact of cyclophosphamide, G-CSF and pegfilgrastim mobilization on lymphocyte, NK and Treg cell counts during mobilization, in the leukapheresis product and after AHSCT in newly diagnosed patients treated with bortezomib and dexamethasone.

Our study shows that mobilization with cyclophosphamide resulted in lower absolute lymphocyte and NK cell counts as compared to growth factor only mobilization (Figure 1) and as a conse- 
TABLE 2. Mean lymphocyte (Lym), natural killer (NK) and T regulatory (Treg) cell counts with $95 \%$ confidence interval (CI) before mobilization, on collection day, in the leukapheresis product and on day 15 after autologous hematopoietic stem cell transplantation (D+15) for mobilization regimens using cyclophophamide, filgrastim (G-CSF) and pegfilgrastim

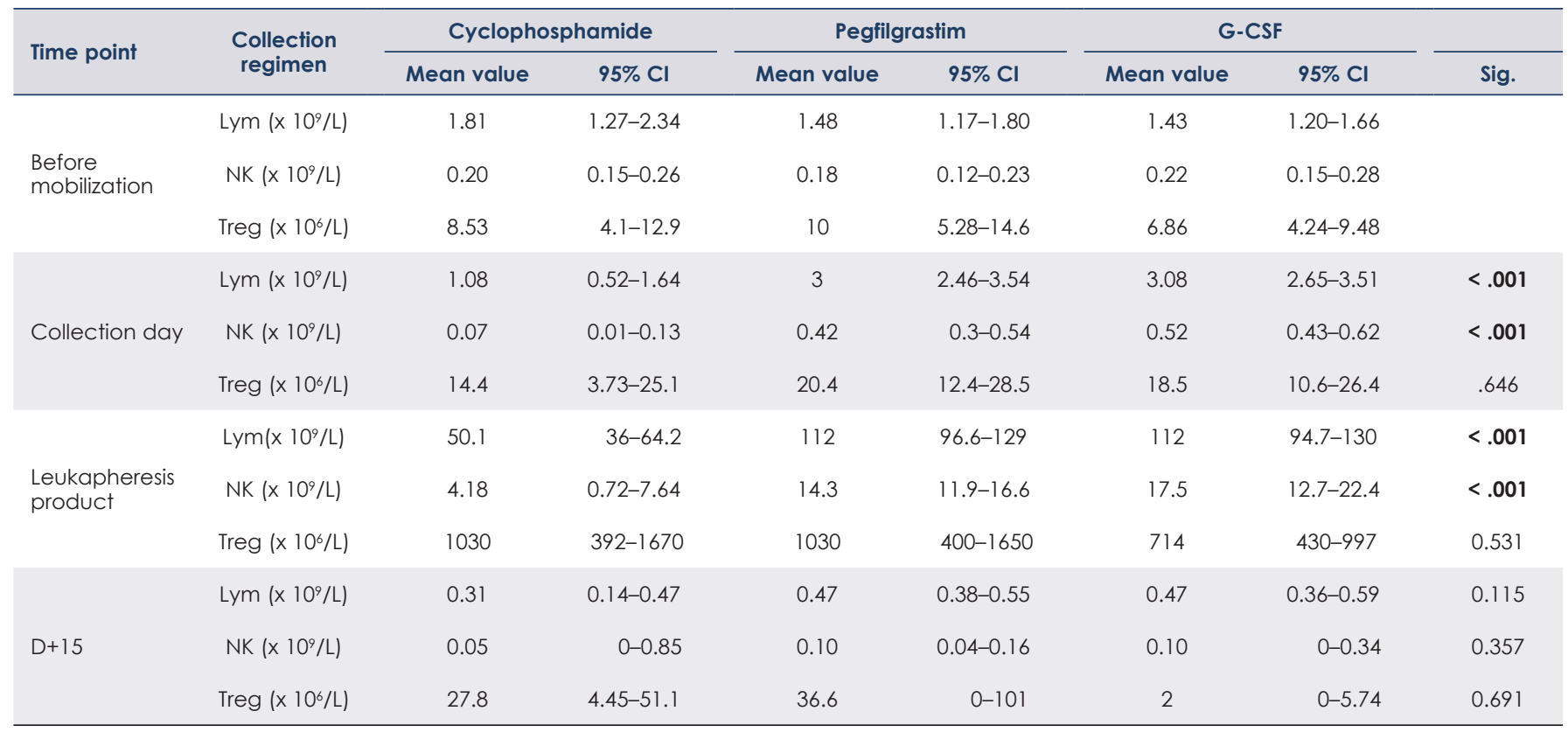

Lym = lymphocytes; NK = natural killer cells; Treg = T regulatory cells

quence the leukapheresis products also contained lower counts of lymphocytes and NK cells. It resulted in slower reconstitution of lymphocytes on day 15 after AHSCT in patients mobilized with cyclophosphamide as compared to those mobilized with growth factors only. The number of lymphocytes and NK cells is important because studies have shown that the infused dose of lymphocytes and the early recovery affects survival in patients after AHSCT suggesting a graft-vs-myeloma effect. ${ }^{12-15,24}$ Counts of at least $0.5 \times 10^{9} / \mathrm{L}$ lymphocytes on day 15 after AHSCT predict better OS in patients with MM. ${ }^{13}$ In our group 2 out of 9 patients receiving cyclophosphamide mobilization achieved this cutoff value as opposed to 7 out of 19 and 9 out of 17 patients receiving G-CSF and pegfilgrastim mobilization, respectively. Besides a graft-vs-myeloma effect, the early reconstitution of lymphocytes and NK cells protects against viral infections including cytomegalovirus, influenza virus, HIV-1, and hepatitis $C$ virus thereby decreasing infectious complications after AHSCT and possibly increasing the age limit of patients eligibly for AHSCT. 25,26

Our findings encourage further research because of the expanding use of lenalidomide consolidation and maintenance after AHSCT. Lenalidomide activity is partly exerted through immunomodulation and activation of NK cells. ${ }^{27,28}$ Therefore per- sistent lower lymphocyte and NK cell counts after AHSCT may decrease the efficacy of lenalidomide in cyclophosphamide mobilized patients. Trials on lenalidomide maintenance have not focused on the impact of the mobilization regimen or lymphocyte subpopulations on treatment outcome. ${ }^{3,29}$

Treg cells are associated with MM progression, probably through immunosuppression and inhibition of NK cell function. ${ }^{16-19}$ Previous studies show that low doses of cyclophosphamide are highly toxic to Treg cells. ${ }^{20}$ In contrast, Condomines in a study of 14 patients mobilized with high dose cyclophosphamide found a 2-fold increase in Treg cells, speculating that a cytokine burst following aplasia due to cyclophosphamide is responsible. ${ }^{11}$ Our data shows a 2-fold increase in Treg cells on collection day compared to baseline value before mobilization in all three mobilization regimens. We speculate that growth factors (G-CSF and pegfilgrastim) are responsible for the increase in Treg cell counts and not the cytokine burst following aplasia due to cyclophosphamide. Evidence from animal models show that G-CSF has a strong effect on promotion of Treg cell numbers and function. ${ }^{30,31}$ A small clinical trial on 29 patients receiving mobilization with high doses of filgrastim (16 $\mathrm{mcg} / \mathrm{kg}$ ) showed that, in addition to stem cells, Treg cell counts increased during mobilization. ${ }^{32}$ 
On day 15 after AHSCT Treg cells are the only subpopulation with higher counts compared to baseline value before mobilization and the value on collection day. Our data shows a 4-fold higher Treg cell count on day 15 after AHSCT as compared to baseline value before mobilization and 2-fold higher as compared to the value on the collection day. We speculate that G-CSF application after AHSCT is the major contributor for the increase of Treg cells on day 15 after AHCST and not growth factors given during mobilization. The lower value of Treg cells on day 15 after AHSCT in the G-CSF regimen cannot be properly evaluated due to the small patient group.

In our study we investigated two different growth factors, namely G-CSF and the long acting pegfilgrastim. Stem cell mobilization with both growth factors results in comparable toxic profiles and a similar recovery of leukocytes and platelets after AHSCT. ${ }^{8}$ However, results from small trials suggest that pegfilgrastim mobilizes a different CD34+ cell subset due to higher expression levels of various genes indicative of early haematopoiesis. ${ }^{33,34}$ Whether this has an impact on lymphocyte subpopulations is not known from the available literature. Our study shows that both growth factors are comparable regarding the increase in lymphocytes, NK and Treg cells during mobilization and in the leukapheresis product. Counts on day 15 after AHSCT are comparable, except Treg cell counts, which are primarily a result of G-CSF application after AHSCT and not during mobilizaton (Table 2).

In the current study we enrolled only patients receiving induction with bortezomib and dexamethasone. Triple agent induction including cyclophosphamide or immunomodulatory drugs is currently the standard induction regimen. ${ }^{4,35}$ Weekly applications of cyclophophamide during induction might decrease Treg cells and improve the immune status of patients before mobilization resulting in a different composition of the leukapheresis product and altered reconstitution after AHSCT. In addition, the optimal dose and interval of cyclophosphamide on Treg cell depression is not known. To answer these questions further investigator driven studies are needed.

Our study has some limitations. Other factors may influence the reconstitution of lymphocyte subpopulations after AHSCT. The transplantation of cells expressing dipeptidyl peptidase-4 (CD26) has been shown to influence reconstitution of lymphocyte subpopulations. Monocytes expressing CD26+ improve the reconstitution of helper, suppressor and NK lymphocytes and a higher number of transplanted CD26+ lymphocytes accelerates the reconstitution of NK lymphocytes. ${ }^{36}$ Cotransplantation of mesenchymal stromal cells during AHSCT improves lymphocyte recovery after AHSCT. ${ }^{37}$

In summary, we found no differences between G-CSF and pegfilgrastim mobilization regarding the increase in lymphocytes, NK and Treg cells during mobilization and in the leukapheresis product. Therefore mobilization with pegfilgrastim is comparable to G-CSF regarding lymphocyte subpopulations and can be used instead for stem cell mobilization. Our results show that mobilization with cyclophosphamide reduces the number of lymphocytes and NK cells on collection day and in the leukapheresis product thereby reducing the absolute number of lymphocytes on day 15 post AHSCT. Hence, cyclophophamide mobilization might decrease graft-vs-myeloma effect possibly affecting the outcome of AHSCT.

\section{References}

1. Gay F, Oliva S, Petrucci MT, Conticello C, Catalano L, Corradini P, et al. Chemotherapy plus lenalidomide versus autologous transplantation, followed by lenalidomide plus prednisone versus lenalidomide maintenance, in patients with multiple myeloma: a randomised, multicentre, phase 3 trial. Lancet Oncol 2015; 16: 1617-29.

2. Lonial S, Boise LH, Kaufman J. How I treat high risk myeloma. Blood 2015 126: $1536-43$.

3. Palumbo A, Cavallo F, Gay F, Raimondo F, Yehudda DB, Petrucci MT, et al Autologous transplantation and maintenance therapy in multiple myeloma. N Engl J Med 2014; 371: 895-905.

4. Zver S, Mlakar U. Slovenske smernice za obravnavo diseminiranega plazmocitoma 2015. Zdr Vestn 2015; 84: 335-51.

5. Mohty M, Harousseau JL. Treatment of autologous stem cell transplant-eligible multiple myeloma patients: ten questions and answers. Haematologica 2014; 99: 408-16

6. Silvennoinen $R$, Anttila $P$, Säily $M$, Lundan $T$, Heiskanen J, Siitonen $\mathrm{TM}$, et al. A randomized phase II study of stem cell mobilization with cyclophosphamide+G-CSF or G-CSF alone after lenalidomide-based induction in multiple myeloma. Bone Marrow Transplant 2015; 51: 372-6.

7. Kuan JW, Su AT, Wong SP, Sim X, Toh SG, Ong TC, et al. A randomized double blind control trial comparing filgrastim and pegfilgrastim in cyclophosphamide peripheral blood hematopoietic stem cell mobilization. Transfus Apher Sci 2015; 53: 196-204.

8. Kim MG, Han N, Lee E-K, Kim T. Pegfilgrastim vs filgrastim in PBSC mobilization for autologous hematopoietic SCT: a systematic review and metaanalysis. Bone Marrow Transplant 2015; 50: 523-30.

9. Gertz M, Kumar S, Lacy M, Dispenzieri A, Hayman S, Buadi F, et al. Comparison of high-dose $\mathrm{CY}$ and growth factor with growth factor alone for mobilization of stem cells for transplantation in patients with multiple myeloma. Bone Marrow Transplant 2009; 43: 619-25.

10. Hamadani M, Kochuparambil ST, Osman S, Cumpston A, Leadmon S, Bunner $\mathrm{P}$, et al. Intermediate-dose versus low-dose cyclophosphamide and granulocyte colony-stimulating factor for peripheral blood stem cell mobilization in patients with multiple myeloma treated with novel induction therapies. Biol Blood Marrow Transplant 2012; 18: 1128-35. 
11. Condomines M, Quittet P, Lu Z-Y, Nadal L, Latry P, Lopez E, et al. Functional regulatory $T$ cells are collected in stem cell autografts by mobilization with high-dose cyclophosphamide and granulocyte colony-stimulating factor. $J$ Immunol 2006; 176: 6631-39.

12. Porrata LF, Inwards DJ, Ansell SM, Micallef IN, Johnston PB, Gastineau DA et al. Early lymphocyte recovery predicts superior survival after autologous stem cell transplantation in non-Hodgkin lymphoma: a prospective study. Biol Blood Marrow Transplant 2008; 14: 807-16.

13. Porrata LF, Gertz MA, Inwards DJ, Litzow MR, Lacy MQ, Tefferi A, et al. Early lymphocyte recovery predicts superior survival after autologous hematopoietic stem cell transplantation in multiple myeloma or non-Hodgkin lymphoma. Blood 2001; 98: 579-85.

14. Kim H, Sohn H-J, Kim S, Lee JS, Kim WK, Suh C. Early lymphocyte recovery predicts longer survival after autologous peripheral blood stem cell transplantation in multiple myeloma. Bone Marrow Transplant 2006; 37: 1037-42.

15. Jimenez-Zepeda $\mathrm{VH}$, Reece DE, Trudel S, Chen C, Franke N, Winter A et al. Absolute lymphocyte count as predictor of overall survival for patients with multiple myeloma treated with single autologous stem cell transplant. Leuk Lymphoma 2015; 56: 2668-73.

16. Oleinika K, Nibbs RJ, Graham GJ, Fraser AR. Suppression, subversion and escape: the role of regulatory $T$ cells in cancer progression. Clin Exp Immunol 2013; 171: 36-45.

17. Ghiringhelli F, Ménard C, Terme M, Flament C, Taieb J, Chaput N, et al. $\mathrm{CD} 4+\mathrm{CD} 25+$ regulatory $T$ cells inhibit natural killer cell functions in a transforming growth factor-beta-dependent manner. J Exp Med 2005; 202: 1075-85.

18. Joshua DE, Brown RD, Ho PJ, Gibson J. Regulatory T cells and multiple myeloma. Clin Lymphoma Myeloma 2008; 8: 283-6.

19. Dosani T, Carlsten M, Maric I, Landgren O. The cellular immune system in myelomagenesis: NK cells and T cells in the development of myeloma and their uses in immunotherapies. Blood Cancer J 2015; 5: e321.

20. Sharabi A, Haran-Ghera N. Immune recovery after cyclophosphamide treatment in multiple myeloma: implication for maintenance immunotherapy. Bone Marrow Res 2011; 2011: 269519.

21. Rajkumar SV, Harousseau JL, Durie B, Anderson KC, Dimopoulos M, Kyle $R$, et al. Consensus recommendations for the uniform reporting of clinical trials: report of the International Myeloma Workshop Consensus Panel 1. Blood 2011; 117: 4691-5.

22. Olivieri A, Marchetti M, Lemoli R, Tarella C, lacone A, Lanza F, et al. Proposed definition of "poor mobilizer" in lymphoma and multiple myeloma: an anaIytic hierarchy process by ad hoc working group Gruppo ItalianoTrapianto di Midollo Osseo. Bone Marrow Transplant 2012; 47: 342-351.

23. Moreau $P$, Facon $T$, Attal $M$, Hulin $C$, Michallet $M$, Maloisel $F$, et al. Comparison of $200 \mathrm{mg} / \mathrm{m}(2)$ melphalan and 8 Gy total body irradiation plus $140 \mathrm{mg} / \mathrm{m}(2)$ melphalan as conditioning regimens for peripheral blood stem cell transplantation in patients with newly diagnosed multiple myeloma: final analysis of the Intergroupe Fra. Blood 2002; 99: 731-5.

24. Porrata LF, Markovic SN. Timely reconstitution of immune competence af fects clinical outcome following autologous stem cell transplantation. Clin Exp Med 2004; 4: 78-85.

25. Lee SE, Yahng SA, Cho BS, Eom KS, Kim YJ, Kim HJ, et al. Lymphocyte subset analysis for the assessment of treatment-related complications after autologous stem cell transplantation in multiple myeloma. Cytotherapy 2012; 14: 505-12.

26. Jost S, Altfeld M. Control of human viral infections by natural killer cells. Ann Rev Immunol 2013; 31: 163-94.

27. Semeraro M, Vacchelli E, Eggermont A, Galon J, Zitvogel L, Kroemer G, et al. Trial Watch: Lenalidomide-based immunochemotherapy. Oncoimmunology 2013; 2: e26494.

28. Lagrue K, Carisey A, Morgan DJ, Chopra R, Davis DM. Lenalidomide aug ments actin remodeling and lowers NK-cell activation thresholds. Blood 2015; 126: 50-60.

29. Attal M, Lauwers-Cances V, Meril G, Caillot D, Moreau P, Facon T, et al. Lenalidomide maintenance after stem-cell transplantation for multiple myeloma. N Engl J Med 2012; 366: 1782-91.
30. Adeegbe D, Serafini P, Bronte V, Zoso A, Ricordi C, Inverardi L. In vivo induction of myeloid suppressor cells and CD4(+)Foxp3(+) T regulatory cells prolongs skin allograft survival in mice. Cell Transplant 2011; 20: 941-54.

31. Rutella S, Zavala F, Danese S, Kared H, Leone G. Granulocyte ColonyStimulating Factor: A Novel Mediator of T Cell Tolerance. J Immunol 2005; 175: 7085-91.

32. Vela-Ojeda J, García-Ruiz Esparza MA, Reyes-Maldonado E, JimenezZamudio L, Garcia-Latorre E, Moreno-Lafont M, et al. Peripheral blood mobilization of different lymphocyte and dendritic cell subsets with the use of intermediate doses of G-CSF in patients with non-Hodgkin's lymphoma and multiple myeloma. Ann Hematol 2006; 85: 308-14.

33. Kobbe G, Bruns I, Fenk R, Czibere A, Haas R. Pegfilgrastim for PBSC mobilization and autologous haematopoietic SCT. Bone Marrow Transplant 2009, 43: 669-77.

34. Bruns I, Steidl U, Fischer JC, Czibere A, Kobbe G, Raschke S, et al. Pegylated granulocyte colony-stimulating factor mobilizes CD34+ cells with different stem and progenitor subsets and distinct functional properties in comparison with unconjugated granulocyte colony-stimulating factor. Haematologica 2008; 93: 347-55.

35. Engelhardt M, Terpos E, Kleber M, Gay F, Wasch R, Morgan G, et al. European Myeloma Network recommendations on the evaluation and treatment of newly diagnosed patients with multiple myeloma. Haematologica 2014; 99: $232-42$.

36. Kopinska A, Krawczyk-Kulis M, Dziaczkowska-Suszek J, Bieszczad K, Jagoda $\mathrm{K}$, Kyrcz-Krzemien $\mathrm{S}$. The importance of the number of transplanted cells with dipeptidyl peptidase-4 expression on the haematopoietic recovery and lymphocyte reconstitution in patients with multiple myeloma after autologous haematopoietic stem-cell transplantation. Hematol Oncol 2015; doi.10.1002/hon.2267.

37. Batorov EV, Shevela EY, Tikhonova MA, Batorova DS, Ushakova GY, Sizikova $\mathrm{SA}$, et al. Mesenchymal stromal cells improve early lymphocyte recovery and $\mathrm{T}$ cell reconstitution after autologous hematopoietic stem cell transplantation in patients with malignant lymphomas. Cell Immonol 2015; 297: 80-6. 